Research Article

\title{
Risk Aversion of Public Service Marketization Based on Fuzzy Analytic Hierarchy Process
}

\author{
Shoubin $Q i^{1}$ and Junwen Feng $\mathbb{D}^{2}$ \\ ${ }^{1}$ School of Intellectual Property NUST, Nanjing University of Science and Technology, Nanjing 210094, Jiangsu, China \\ ${ }^{2}$ School of Economics and Management NUST, Nanjing University of Science and Technology, Nanjing 210094, Jiangsu, China
}

Correspondence should be addressed to Junwen Feng; qishoubin@njust.edu.cn

Received 8 December 2020; Revised 23 February 2021; Accepted 19 March 2021; Published 30 March 2021

Academic Editor: Ming Bao Cheng

Copyright (c) 2021 Shoubin Qi and Junwen Feng. This is an open access article distributed under the Creative Commons Attribution License, which permits unrestricted use, distribution, and reproduction in any medium, provided the original work is properly cited.

\begin{abstract}
With the development of China's economy, people's demand for public services is increasing. While meeting the public better through marketization, it is also easy to lead to some risks. The purpose of this study is to use the fuzzy analytic hierarchy process (FAHP) to evaluate the risk of public service marketization and make effective measures to avoid it. This study selects the Public Gymnasiums in different districts of our city as the research object and selects one as the nationalized public service place and the other as the market-oriented public service place. In this study, the amount of service, service equipment, service supervision status, and people's score under the situation of nationalization and marketization is used as the evaluation indexes of public service marketization. At the same time, combined with the fuzzy analytic hierarchy process (FAHP), the risks to the normal operation of the place after marketization are summarized. The results show that the turnover of the nationalized public service places is about 40 million yuan in the past five years, and the capital flow rate gradually decreases from $1.5 \%$; while the market-oriented turnover reaches the maximum of 90 million yuan, the capital flow rate also rises to $2.21 \%$. However, with the marketization, the scores are high and low. This shows that the marketization of public services leads to the improvement of service items and the increase of service charges. The conclusion is that the marketization of public services will have certain risks, but with the control and fine adjustment of enterprises, it is gradually supported by the public.
\end{abstract}

\section{Introduction}

New public management reform has appeared in the world. The marketization of public service is the main one [1]. It breaks the monopoly supply mode of the traditional public service government, introduces the market competition mechanism, and establishes a diversified supply organization with separation of production and supply. The key point of the composite model is the change in the quality and efficiency of public service supply. The marketization of public services has proved a considerable reform practice in improving the quality and efficiency of public services, reducing the financial pressure of the government, improving national satisfaction [2], and promoting the construction of a service-oriented government and a clean and efficient government. The marketization of public service has brought new brilliance and vitality to the previously stopped public service. The reform plan with market intention has become the common choice of the government's public service reform.

The improved analytic hierarchy process method and fuzzy analytic hierarchy process are combined with qualitative evaluation and quantitative evaluation to comprehensively evaluate the market-oriented risk of public service [3] and lay a solid foundation for risk prevention and control. Moreover, the risk assessment suitable for enterprises is not only to meet the needs of market risk management but also to consider the principle of cost and benefit, improve the level of risk assessment and risk management in the public service market, effectively prevent the mechanization of risk assessment of comprehensive risk, and try to establish a risk caused by the lack of risk assessment after reform [4]. 
In his research on the marketization of public services, lunt analyzes a neglected factor in the marketization of public services. He examines overseas trade activities in the fields of health and criminal justice. This paper discusses the differences between these departments, their policies, and their driving forces. His focus on contrasting experiences is an opportunity to understand the complex and differentiated operational and structural environments in which this form of "public entrepreneurship" is expressed. The accuracy of his method is not high [5]. Gang and Hanwen think the provision of public services should be both universal, that is, independent of the social or economic status of the recipients, and contextual, that is, able to compensate for different local needs and conditions. Coordinating these two attributes requires various forms of innovation, mainly digital public service innovation. Based on the four-stage model of the United Nations e-government survey, this paper proposes a framework for developing such innovation, and takes transparency, participation, anticipation, personalization, CO creation, situational awareness, and situational intelligence services (including actual cases) as the initial set of innovation. It also outlines the new technology, organizational and policy related government capabilities needed to participate in digital public service innovation [6]. But its approach is not stable [7]. In the study of Rajabi F, fuzzy analytic hierarchy process (FAHP) and fuzzy additive ratio evaluation (ARAS-F) were used to identify and rank the control measures of violence among medical staff. In the first stage, through the review of previous studies, his method identified and extracted the most common violence standards and control programs. In the next phase, he uses the FAHP criteria for priority control measures. Finally, he used the ARAS-F method to give priority to control measures of workplace violence. His method is not practical [8]. Gaber et al.'s research attempts to overcome the lack of reliable estimation of Malaysian users' willingness to pay for public transport (especially buses) through a fuzzy analytic hierarchy process (FAHP) [9]. This is a breakthrough research. He tries to evaluate the satisfaction factors of bus users based on FAHP and uses the application to find the pattern of WTP characteristics by shortening travel time. Data were collected from public transport users' intentions in Kuala Lumpur, Malaysia. His method is not convincing [10].

This paper first introduces the concept of public service and the detailed problems encountered in the process of marketization. Then, it also describes the risk aversion of payment methods and risk research methods, including literature induction, questionnaire survey, and quantitative and qualitative analysis. This research mainly uses the fuzzy analytic hierarchy process, which is mainly composed of a fuzzy judgment matrix and analytic hierarchy process. This study takes the public sports facilities in different districts of our city as the research object and, respectively, discusses the development status and the public evaluation under the situation of nationalization and marketization. Combined with the experimental results, this paper analyzes the current situation of public service market-oriented project supervision, the importance of regulatory measures, the market-oriented business amount analysis, and scoring analysis. So as to avoid the risk of public service marketization, this paper mainly studies the risk aversion of public service marketization based on a fuzzy analytic hierarchy process. First of all, using the method of literature review, this paper gives a brief overview of public service and fuzzy analytic hierarchy process, then establishes the model of this paper combined with the two, and finally analyzes all aspects of public service according to the model.

\section{Marketization of Public Service and Fuzzy Analytic Hierarchy Process}

2.1. Concept of Public Service. In our country, the main areas of public service are public security service, public sports service, public health service, public education service, public security service, public law service, and public policy service. Because the field of public service is very extensive, we cannot use a unified concept to define the "public service." At present, the main opinions on "public service" are as follows $[11,12]$.

First, in our country, public service is one of the contents of "serving the people" that the government often emphasizes. The general attribute of responsibility and work is a common term in all government work to make up for the defects of the market and promote social justice. Second, public service refers to the responsibility, and responsibility of the government led public goods and service departments to produce and supply pure public goods, public goods, mixed public goods, and special folk goods. It refers to the public goods and services produced by the whole society for common consumption and equal enjoyment. Fourth, public service refers to the public goods produced by the government and nongovernmental organizations in the process of handling public business [13].

\subsection{Problems in the Process of Public Service Marketization}

2.2.1. Lack of Public Responsibility Brought by Marketization. In the process of market-oriented reform, some local governments are more worried about the change of government functions, the reduction of personnel, and the solutions to financial and investment problems [14], but they have not formulated countermeasures and underestimated the potential gap of public responsibility after marketization. We hope to take preventive measures or reduce the responsibility of the government subjectively. Because enterprises and nongovernmental organizations have no obligation to undertake social public responsibility, they sometimes lose public responsibility for the purpose of pursuing interests. Therefore, the government cannot bear the public responsibility; on the contrary, it should formulate the relevant laws and regulations for the management and supervision of enterprises and nongovernmental organizations and bear the corresponding responsibilities [15]. Public service can be marketized, but public responsibility cannot be marketized $[16,17]$. 
2.2.2. Marketization Causes the Loss of State-Owned Assets. The loss of state-owned assets, reflected in the loss of government finance and state-owned enterprises, will eventually damage the interests of the state. Taking the cooperation between the government and the people as an example, the government uses several public service projects such as infrastructure construction, water supply, and power supply to cooperate with nonstate-owned funds [18], and each party has a certain share. Due to the lack of funds from the state-owned government, the proportion of joint ventures is only offset by the discount of fixed assets, and the nonstate-owned capital actually contributes to the capital [19].

This general marketization method is due to the reformers' lack of necessary knowledge and skills, the lack of perfect supervision and restriction mechanism, and the lack of scientific evaluation methods [20], resulting in the direct loss of state-owned assets (improper behavior of managers) and indirect losses (under evaluation). This kind of situation often occurs in the early stage of marketization, especially the asset loss of small and medium-sized state-owned enterprises with poor efficiency.

2.2.3. Marketization Causes Fairness Problems. Public services and the security of public services must be fair and just, reflecting social equity to the maximum extent. Public service is not inherent to a few people but must have universal significance. However, the marketization of public services follows the same exchange principle. The services with low payment capacity or no services at all decline and cannot be accessed. The hierarchical situation of public services is formed. On the premise of insufficient total public services, the disadvantaged groups can obtain very few public service goods, which cannot meet their basic living needs [21, 22].

In the market situation, in order to improve profits, producers will choose the service items with high profitability, but the profitability is low, but they may be denied to provide the services that need to be provided. Consumers can choose various types and levels of services [23], but people who live in difficulties have limited ability to pay, so they lose the right to choose [24].

\subsection{Risk Aversion of Payment Methods in Public Services.} Government functions must strictly control the scope of user payment for applications. The user's payment is only applicable to the relatively high operating cost and crowded public facilities resources and does not import the user's payment to the project with a lower operating cost.

In order to prevent the complete privatization of public resources, it is necessary to monitor the price of public goods, control the price within a reasonable range, and adopt subsidies to socially disadvantaged groups to ensure the publicity principle of public service supply. This can effectively avoid the risk of this model $[25,26]$.

In short, in the case of market economy, the supply of public sports must follow the application form of market intention. In this case, the cost is inevitable and is the necessary condition to maintain the public supply. In the user charging mode, in order to solve the problem of price setting mechanism, the two-part price setting method is relatively advanced. It has the value of practical application and improvement. At the same time, this market-oriented application mode needs to pay attention to the possible risks and strengthen the use of risk management.

\subsection{Research Methods of Public Service Marketization Risk}

(1) Literature induction: most of the research results used in the coding part of the theory are obtained from the library and Internet resources. After reading a lot of domestic and foreign public service outsourcing knowledge, they have formed their own unique series of knowledge systems and selected a valuable part for research. The theory and literature summary used in this paper will be obtained through comparison [27, 28].

(2) Qualitative analysis: the research idea starts from the research results at home and abroad, summarizes the research results of previous scholars, points out the nature of public service outsourcing directly, and puts forward the research framework of this paper, which determines that the decision-making stage, implementation stage, and introduction stage of service outsourcing process are divided into two stages [29]. The corresponding risk avoidance strategies are proposed from three aspects.

(3) Quantitative analysis method: in the qualitative analysis of public service outsourcing, the risk of public service outsourcing is quantified through a data model, which makes the analysis results more convincing [30].

(4) Questionnaire survey method: as a case study, through the questionnaire survey of government agencies and the corresponding third-party service consulting agencies, we get valuable data, conduct model analysis, and finally grasp the risk situation of China's public service outsourcing [31].

\subsection{Fuzzy Analytic Hierarchy Process}

2.5.1. Analytic Hierarchy Process. Analytic hierarchy process is a systematic and multifunctional decision analysis method with a multilevel structure, which is characterized by the combination of qualitative analysis and quantitative analysis. Enterprise risk assessment and analysis is a complex practical problem. After the application of the analytic hierarchy process, the indicators of multiple complex problems are found, and they are decomposed into target level, benchmark level, index level, and other levels to form a hierarchical evaluation model. By selecting a specific quantitative proportion, all indicators are quantified to the same level, and the judgment matrix is constructed by a pairwise comparison of indicators. Through the individual ranking of each level and the ranking of the whole level, the relative importance of the indicators is determined, and the indicators are analyzed and judged by calculating the weight of 
the indicators, and finally, a comprehensive decision is made. The model architecture of the analysis hierarchy process is shown in Figure $1[32,33]$.

2.5.2. Calculation Steps of Analytic Hierarchy Process. The calculation sequence of the analysis hierarchy process is mainly composed of the following contents. The first is to determine the problems of evaluation and analysis, the second is to build a multilevel structure, the third is to form a judgment matrix based on multiple clear hierarchical structures, and the fourth is to implement the hierarchical structure: single sort and whole sort. The specific steps are as follows [34].

The first is to sort out the overall objective of evaluation problems, determine the problems that need decision-making, and clarify the relationship with relevant index elements through comprehensive analysis.

Second, construct a multilevel structure. The multilevel structure model of the analytic hierarchy process is mainly divided into three levels (target, benchmark, and plan). In terms of the number of indicator elements in each level, the target layer is usually uniquely determined, with multiple baseline and planning layers. Indicator elements correspond to indicators at multiple reference levels and indicators at multiple program levels $[35,36]$.

The third is to form a judgment matrix. After comparing the two indicator elements, assume that there are $n$ indicator elements so that the $i$ and $j i \operatorname{target}(i=1,2, \ldots, n)$. The importance degree of the index element is $a_{i j}$, and the $n$ order judgment matrix $\left(a_{i j}\right)_{n \times n}$ is obtained. The determination matrix is the value that compares the importance of index elements at the same level with the importance of corresponding index elements after the previous level. The decision matrix is as follows:

$$
A=\left[\begin{array}{c}
a_{11}, a_{12}, \ldots, a_{1 n} \\
a_{21}, a_{22}, \ldots, a_{2 n} \\
\ldots \\
\ldots \\
a_{n 1}, a_{n 2}, \ldots, a_{n n}
\end{array}\right] .
$$

In the process of analyzing hierarchy, the importance of judgment matrix is judged by the ratio of 1 to 9 . That is, the relative importance indicator can be replaced by a number. Specifically, it can be summarized as simple as 1 , and the two indicator elements are equally important. The numbers 35,7 , and 9 are important benchmarks. Among the two index elements compared, the index element $(i)$ of the former is more important than the index element $(j)$ of the latter, and the second is the slightly important and relative element (Important, very important, especially important). If numbers 2, 4, 6, and 8 are displayed, the relative importance of the two compared index elements is expressed in the middle of the adjacent importance. When the importance is reciprocal of each other, it will reflect the opposite value of

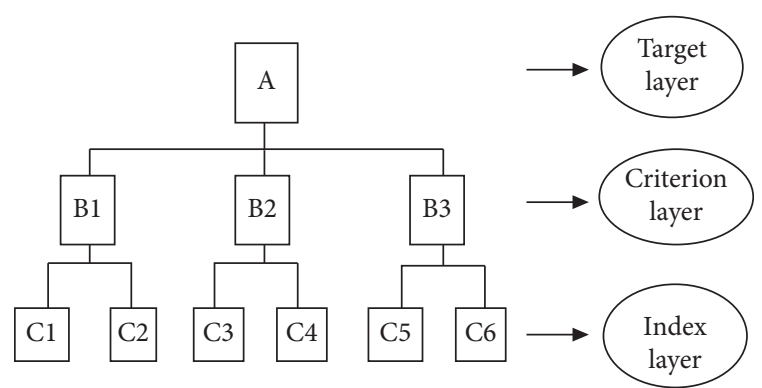

Figure 1: Analytic hierarchy process model architecture.

the importance scale. For example, the importance scale used to compare element index $i$ and element index $j$ is $a_{i j}$, and the importance scale for comparing element index $j$ with element index $i$ is $1 / a_{i j}$.

If the index elements of the judgment matrix are determined by the ratio of 1 to 9 , the matching index of the judgment matrix needs to be tested:

$$
\mathrm{CI}=\frac{\left(\lambda_{\max }-n\right)}{(n-1)} .
$$

The match index of the determined matrix depends on the value of CI. For the calculation results, the larger the CI value, the greater the matching deviation of the judgment matrix. On the contrary, the smaller the calculated value of $\mathrm{Ci}$, the lower the consistency of the decision matrix and the greater the degree. In addition, the calculated value of CI will also be affected by the order of the decision matrix. With the increase of the calculated value of $\mathrm{Ci}$, the influence of deviation will gradually increase. The average random matching index is imported into the decision matrix [37]. Thus, the order of the decision matrix can be prevented from affecting the integrated index CI. The random index is omitted as RI, and its value depends on the order [38].

When judging the matching of the matrix, the order of the matrix is used as a reference. When the matrix is completely matched, the order of the matrix is 1 or 2 . If the order of $\mathrm{CR}$ is greater than 3 , the random matching rate must be calculated in the matching check:

$$
\mathrm{CR}=\frac{\mathrm{CI}}{\mathrm{RI}}
$$

The reference standard of the matrix matching test is random matching ratio $C R=0.1$. When $C r$ is less than 0.1 , it means that the decision matrix has passed the integration test. Otherwise, the decision matrix does not meet the requirements of integration testing. At this point, the judgment value needs to be adjusted to pass the integration test.

The fourth is to solve the hierarchical ranking of weights. There are two kinds of hierarchical sorting: first level sorting and total level sorting. For single rank sorting, the maximum eigenvalue of the determined matrix must be calculated. The maximum eigenvalue has the corresponding eigenvector calculation [39]. The calculation method includes root 
detection and multiplication. After sorting the importance of index elements at the same level as the parent level, the total level is sorted based on the sorting results.

2.5.3. Fuzzy Judgment Matrix. The weight of the fuzzy judgment matrix is calculated. In the process of fuzzy analysis hierarchy, it is necessary to use a fuzzy decision matrix to calculate the weight. The calculation method of weight:

$$
\omega_{i}=\frac{\left(\sum_{j=1}^{n} a_{i j}+(n / 2)-1\right)}{n(n-1)} .
$$

When the vector $\omega=\left(\omega_{1}, \omega_{2}, \ldots, \omega_{n}\right)$ is the sorted vector of fuzzy complementary matrix $A$, then the matrix $W$ representing the weight of $a$ is $\left(\omega_{i j}\right)_{n \times n}$, and the values of $\omega_{i j}=\omega_{i}-\omega_{j}+0.5, i$ and $j$ are $1,2, \ldots, n$.

In the process of fuzzy analysis hierarchy, the construction of a fuzzy decision matrix is completed. After checking the consistency of the fuzzy decision matrix, the ranking of single level and total level is calculated according to the same steps as the analysis hierarchy process. The single time method of each level is consistent with the analytic hierarchy process. In this paper, the characteristic root method is used.

(1) Calculate the total of each column in the fuzzy matrix:

$$
a_{j}=\sum_{i=1}^{n} a_{i j} \quad(i, j=1,2, \ldots, n) .
$$

(2) The standard fuzzy decision matrix is established. The elements of the fuzzy decision matrix are divided by the sum of the corresponding columns to obtain a new fuzzy decision matrix:

$$
b_{i j}=\frac{a_{i j}}{a_{j}} \quad(i, j=1,2, \ldots, n) .
$$

(3) Get the normalized weight of each indicator element. Specifically, the average value of each row of the standard fuzzy judgment matrix is calculated:

$$
b_{j}=\frac{\sum_{j=1}^{n} b_{i j}}{n} \quad(i, j=1,2, \ldots, n) \text {. }
$$

Different from the general analytic hierarchy process, if the fuzzy analytic hierarchy process is adopted, the total ranking weight $w$ is calculated:

$$
w_{j}=\sum_{i=1}^{n} w_{i} w_{i j}
$$

where $w_{j}$ represents the $j-$ th index element of the total weight $w$ of the hierarchy; $w_{i}$ represents the weight of the $i$ - th criterion level relative to the total target level; $w_{i j}$ represents the weight of the $j$-th element index corresponding to the $i$ - th criterion level.

\section{Fuzzy Analytic Hierarchy Process Model of Public Service Marketization}

3.1. Research Object. Based on the research on the relevant concepts of the market-oriented mode of urban public sports service supply in China, this study takes 18 swimming pools randomly selected from 9 districts (2 swimming pools in each region) as the investigation objects. This paper mainly investigates the current situation of swimming pool operators, coaches, and other related swimming pool practitioners and social sports organizations participating in public sports service.

\subsection{Model Construction of Fuzzy Evaluation Method}

3.2.1. Establishment of Evaluation Index System. Index system is the basis of fuzzy evaluation and the concrete content of things evaluation. Rating elements, such as audio, can be set at multiple levels as needed. The elements of the first level are "price," "mode," etc. Layers can adjust the mode to surround, 3D, and other sides.

3.2.2. Determination of Evaluation Set. The evaluation set is different from the evaluation index set. It is mainly based on a variety of analysis problems and makes comments on the evaluation results of each interval according to the needs. Its nature is to provide a framework for the final model processing results. According to the needs of evaluation, the evaluation level is divided into different levels (high, medium, low, very good, good, fair, bad, etc.).

3.2.3. Determination of Weight. In the analysis and evaluation, after the indicator system is determined, the importance of these individual indicators must be scored when explaining the items. Because the size of the weight will ultimately have a greater impact on the evaluation results, the determination of the weight is objective, and the weight must be determined as much as possible. There are more in every aspect of the matter. The actual weight coefficient can be flexibly determined according to the characteristics of the evaluated things, but the general principle is that the total weight is 1 regardless of the actual working conditions.

3.2.4. Comprehensive Evaluation Model. After obtaining the weight and the evaluation results of a single element, the final result of the two products must correspond to the evaluation set established in the second step if the annotation corresponding to the maximum value is selected according to the principle of maximum membership, the final result of the evaluation.

\section{Public Service Marketization and Risk Aversion Analysis}

4.1. Analysis of the Current Situation of Public Service Marketization Project Supervision. Since 2013, the Chinese government has paid more attention to the cooperation between the government and the people and has issued a 
series of documents to standardize and explain the cooperation mode between the government and the people, making up for the lack of legal provisions on the current comprehensive cooperation mode between the government and the people. At the same time, it is also an encouragement to the nongovernmental sectors, which provides a good regulatory environment for participating in the cooperation projects between the government and the people, and improves their trust in the cooperation between the government and the people. The evaluators of this paper are the government and enterprises. Public service has always been dominated by the government. However, after the marketization of public service, the participants have become more and more, which can better reflect the determination of the government to marketize public service and also a kind of trust in enterprises. As shown in Figure 2, the limited number of documents issued by the government for government civilian cooperation projects.

Figure 2 shows the number of regulatory documents issued by the government and different governments at various levels for the government people cooperation projects in the past five years. The model is associated. In addition, the report classified the information published on the relevant websites of the Ministry of Finance and found that the regulatory documents were basically guidelines, with few laws and regulations.

\subsection{Analysis of the Importance of Public Service Marketization} Supervision Measures. Next, descriptive statistics will be used to analyze the importance of project related regulatory measures and the significance of project construction supervision and supervision measures and draw corresponding analysis conclusions. The descriptive statistics of project construction supervision measures are shown in Table 1.

According to the data in Table 1, the highest average score is the government's supervision of private sector visits. It is not difficult to understand that a high-quality private sector is key to implementing cooperative projects effectively. Because infrastructure projects need a relatively large amount of funds, the supervision of funds during the construction period is, of course, the third under the supervision of the government. To ensure the safety of funds is not only to ensure the smooth completion of the project but also to prevent corruption and not violate the interests of the society. The statistical description of project service supervision measures is shown in Table 2.

According to the data in Table 2, the highest average score is the supervision of service price. Public facilities in order to use public facilities need to pay a certain fee. If the price is too high, it will not only lose the public welfare attribute of the project but also bring a negative impact to the direct experience of consumers using the project, which will damage the social usefulness of the project. The service quality of the project in use can be directly measured whether the private sector provides high-quality services.

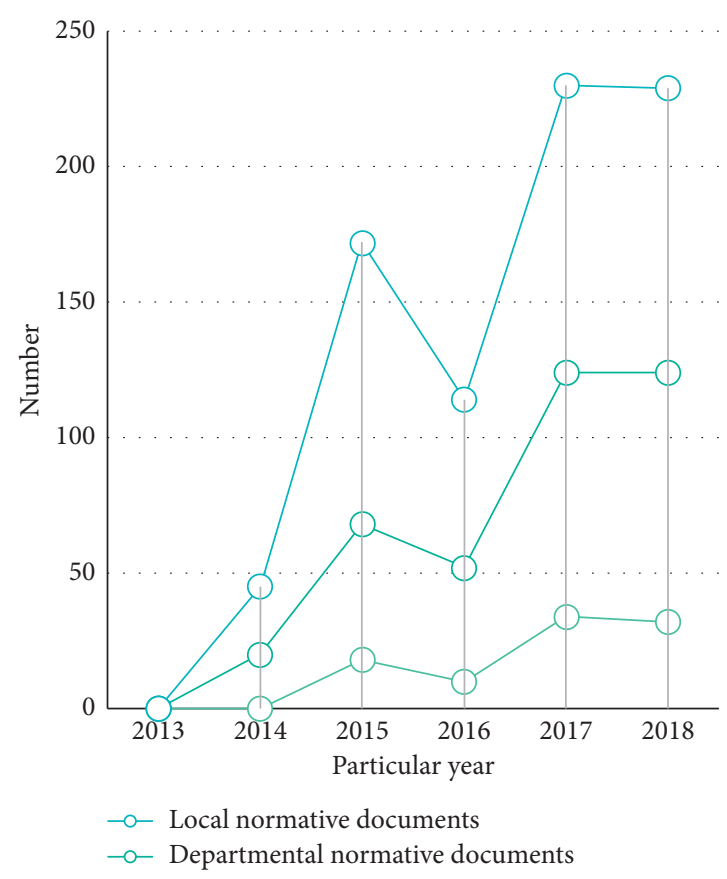

FIGURE 2: Broken line chart of the number of normative documents issued by the government for public private partnership projects.

4.3. Analysis of Business Amount of Public Service Marketization. Figure 3 shows the turnover of nationalization and marketization of public services.

Figure 3 reflects the profitability related data indicators after the marketization of public services. From the point of view of net asset ratio and total profit rate, there are few examples of government control of net assets and total profits. After marketization, capital and profits have increased significantly. This shows that marketization makes the real value and market competition more clear.

Figure 4 shows the capital flow ratio of nationalization and privatization of public services.

As can be seen from Figure 4, the debt data indicators of market-oriented public service companies include current ratio, demand ratio, asset liability ratio, and other indicators to objectively reflect the company's ability in the past five years and test whether it has potential possibility. Investigate whether there are tax risks caused by financial risks and capital flow difficulties. The profitability of a business is inseparable from the effective turnover rate of funds used. The closely related debt indicators are the current ratio, which, respectively, represents the ratio of current assets and current assets to current liabilities. A high current ratio means that assets are highly liquid but not too high. If it is too high, it will occupy more funds, affect the capital turnover rate, and the profitability will decline.

The appropriate benchmark for current ratios is 2 and for current ratios is 1 . In order to measure the capacity of an enterprise, it is necessary to combine the indicators of current ratio and demand ratio. From the changes of the current ratio and current ratio of public service companies in the past five years from 2015 to 2019, both sides have moved 
TABle 1: Descriptive statistics of the importance degree of project construction supervision measures.

\begin{tabular}{lccccc}
\hline & Number of samples & Minimum value & Maximum & Average value & Standard deviation \\
\hline Entry criteria & 74 & 1 & 5 & 4.28 & 0.948 \\
Construction safety & 74 & 1 & 5 & 3.69 & 0.901 \\
Project progress & 74 & 1 & 5 & 3.73 & 1.021 \\
Construction quality & 74 & 2 & 5 & 4.26 & 0.735 \\
Capital security & 74 & 1 & 5 & 3.99 & 1.017 \\
\hline
\end{tabular}

TABle 2: Descriptive statistics of importance degree of project service supervision measures.

\begin{tabular}{lccccc}
\hline & Number of samples & Minimum value & Maximum & Average value & Standard deviation \\
\hline Service quality & 74 & 1 & 5 & 3.99 & 0.934 \\
Service price & 74 & 2 & 5 & 4.13 & 0.891 \\
Operating costs & 74 & 1 & 5 & 3.84 & 1.121 \\
Scope of services & 74 & 1 & 5 & 3.71 & 1.207 \\
\hline
\end{tabular}

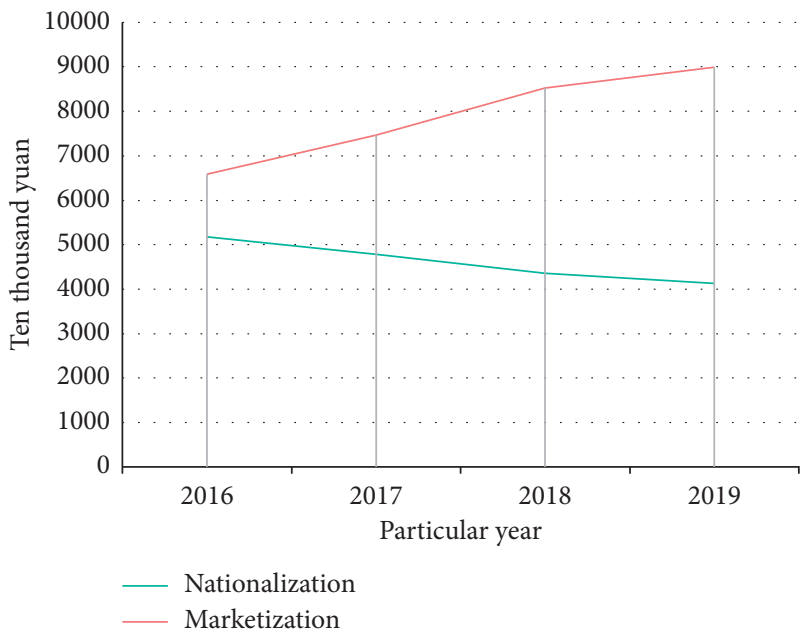

Figure 3: Turnover of nationalization and marketization of public services.

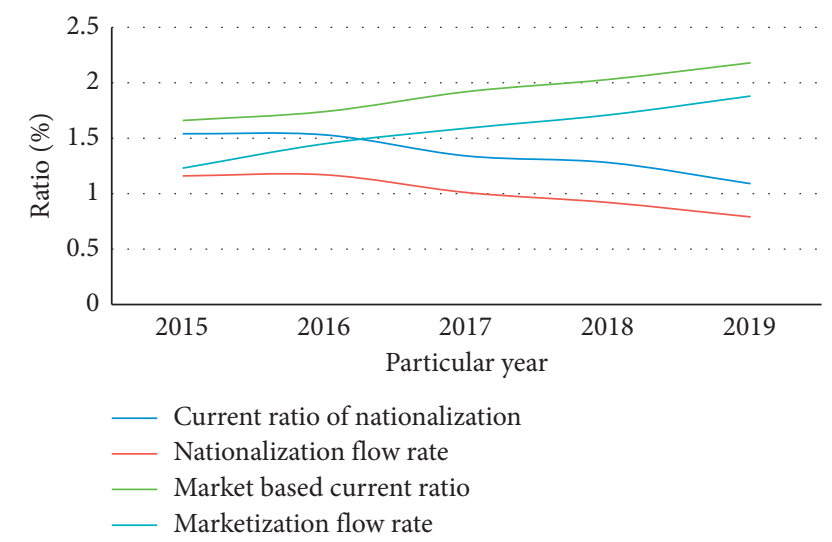

FIgURE 4: Capital flow ratio of nationalization and privatization of public services.

in a relatively stable range. After 2017, the current ratio has increased significantly, close to the reference value of 2 , and the demand ratio has also increased significantly compared with 2018, reflecting the trend of these two indicators. The

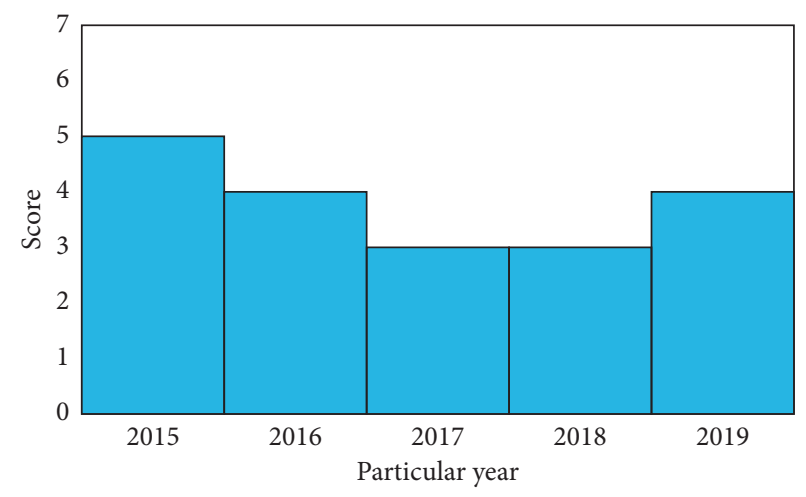

Figure 5: Public service marketization score.

situation and index trend are basically the same, the liquidity of assets is strongly guaranteed, and the company is able to repay its debts. There is no tax risk caused by the company's capital flow difficulties.

4.4. Public Service Analysis Score. Figure 5 shows the public service marketization score.

As can be seen from Figure 5, after the marketization of public services, at first, the public had a high evaluation of the measure, but as time went on, people were dissatisfied with the measure, and the score dropped. It is because the amount of service caused by marketization has increased a lot compared with the previous period, which has been resisted by many people. After that, the phenomenon of improvement shows that the market-oriented public service is improving step by step and moving towards the direction of being more accepted and loved by the people.

\section{Conclusion}

This paper mainly studies the risk aversion of public service marketization based on the Fuzzy Analytic Hierarchy Process (FAHP). It uses the methods of literature review, fuzzy analytic hierarchy process (FAHP), and mathematical model and establishes the risk aversion model of public service marketization. Finally, it analyzes the current 
situation of public service marketization risk in China and distinguishes the risks according to the degree of influence. The research of this paper is mainly through the reform of public service marketization, adjusting government functions, and improving the level of public service optimization governance.

This paper analyzes the marketization of public service from the perspective of government propaganda and discusses the realization and separation of the public service marketization reform plan publicized by the government. This paper discusses the relevant theories and historical process of marketization of public service. Secondly, by comparing the previous public service supply mode with the multiagent supply mode of market intention, this paper analyzes the realization of government propaganda through marketization, mainly including the optimization of market-oriented reform scheme. We should allocate resources, relieve government pressure, break government monopoly, adjust government functions, introduce market mechanisms, improve service efficiency, strengthen citizen participation, and promote the realization of democracy.

The risk of public service marketization is not certain but a dynamic process accompanied by environmental changes. From the government's market-oriented choice to the implementation and supervision of enterprises, and finally, to the evaluation of market-oriented quality, there are various risks in each stage, the types of various risks and the impact on the market-oriented quality of public services. The analysis and comparison of these risk factors and the subsequent risk aversion are the basis of decision-making. In this stage, the marketization of public service should start from reality, improve the system of paying attention to public satisfaction, cultivate and develop social organizations, expand the scope of a public service purchase, improve the supervision and evaluation mechanism of public service marketization, effectively improve the government's optimal governance, avoid risks to the maximum extent, and promote the marketization of public service into standardization and scientific development.

\section{Data Availability}

The data underlying the results presented in the study are available within the manuscript.

\section{Conflicts of Interest}

The authors declare that they have no conflicts of interest.

\section{References}

[1] J. Chen, X. Wang, and Z. Chu, "Capacity sharing, product differentiation and welfare," Economic Research-Ekonomska Istraživanja, vol. 33, no. 1, pp. 107-123, 2020.

[2] H. Kim, "Investigating the mediating role of social networking service usage on the big five personality traits and on the job satisfaction of Korean workers," Journal of Organizational and End User Computing, vol. 31, no. 1, pp. 110-123, 2019.
[3] Y. T. Chen, C. H. Chen, S. Wu, and C. C. Lo, "A two-step approach for classifying music genre on the strength of AHP weighted musical features," Mathematics, vol. 7, no. 1, p. 19, 2019.

[4] Y.-H. Yuan, S.-H. Tsao, J.-T. Chyou, and S.-B. Tsai, "An empirical study on effects of electronic word-of-mouth and Internet risk avoidance on purchase intention: from the perspective of big data," Soft Computing, vol. 24, no. 8, pp. 5713-5728, 2020.

[5] N. Lunt, "The entrepreneurial state: service exports in healthcare and criminal justice," Journal of International \& Comparative Social Policy, vol. 33, no. 1, pp. 1-18, 2017.

[6] L. Gang and Z. Hanwen, "An ontology constructing technology oriented on massive social security policy documents," Cognitive Systems Research, vol. 60, pp. 97-105, 2020.

[7] J. Bertot, E. Estevez, and T. Janowski, "Universal and contextualized public services: digital public service innovation framework," Government Information Quarterly, vol. 33, no. 2, pp. 211-222, 2016.

[8] F. Rajabi, M. Jahangiri, F. Bagherifard, S. Banaee, and P. Farhadi, "Strategies for controlling violence against health care workers: application of fuzzy analytical hierarchy process and fuzzy additive ratio assessment," Journal of Nursing Management, vol. 28, no. 4, pp. 777-786, 2020.

[9] T. Gaber, S. Abdelwahab, M. Elhoseny, and A. E. Hassanien, "Trust-based secure clustering in WSN-based intelligent transportation systems," Computer Networks, vol. 146, pp. 151-158, 2018.

[10] S. J. Hashem, B. Peyman, and Y. Nur, "The combination of a fuzzy analytical hierarchy process and the taguchi method to evaluate the Malaysian users' willingness to pay for public transportation," Symmetry, vol. 8, no. 9, pp. 1-17, 2016.

[11] M. B. Hansen and A. C. Lindholst, "Marketization revisited," International Journal of Public Sector Management, vol. 29, no. 5, pp. 398-408, 2016.

[12] L. Li and R. C. K. Chan, "Contesting China's engagement with neoliberal urbanism," Asian Education and Development Studies, vol. 6, no. 1, pp. 44-56, 2017.

[13] L. T. Christensen, "Passenger rail SOEs as domestic institutional market actors," International Journal of Public Sector Management, vol. 31, no. 2, pp. 128-141, 2018.

[14] J.-Y. Yeh and C.-H. Chen, "A machine learning approach to predict the success of crowdfunding fintech project," Journal of Enterprise Information Management, vol. 28, no. 5, pp. 924-944, 2020.

[15] S.-B. Tsai, R. Saito, Y.-C. Lin et al., "Discussing measurement criteria and competitive strategies of green suppliers from a Green law Perspective," Proceedings of the Institution of Mechanical Engineers, Part B: Journal of Engineering Manufacture, vol. 229, no. S1, pp. 135-145, 2015.

[16] J. Ohlsson and H. Sjøvaag, "Protectionism vs. Non-interventionism: two approaches to media diversity in commercial terrestrial television regulation," Javnost-The Public, vol. 26, no. 1, pp. 70-88, 2018.

[17] M. Gabrielle, T. Lundstrm, M. Sallns et al., "Big business in a thin market: understanding the privatization of residential care for children and youth in Sweden," Social Policy \& Administration, vol. 50, no. 7, pp. 805-823, 2016.

[18] Z. Lv, B. Hu, and H. Lv, "Infrastructure monitoring and operation for smart cities based on IoT system," IEEE Transactions on Industrial Informatics, vol. 16, no. 3, pp. 1957-1962, 2020.

[19] B. Jantz, T. Klenk, F. Larsen et al., "Marketization and varieties of accountability relationships in employment services: 
comparing Denmark, Germany, and great britain," Administration \& Society, vol. 14, no. 3, pp. 501-520, 2016.

[20] Y. Tang and M. Elhoseny, "Computer network security evaluation simulation model based on neural network," Journal of Intelligent \& Fuzzy Systems, vol. 37, no. 3, p. 3197, 2019.

[21] K. Kateřina and J. Havlíková, "Current developments in social care services for older adults in the Czech republic: trends towards deinstitutionalization and marketization," Journal of Social Service Research, vol. 42, no. 2, pp. 180-198, 2016.

[22] T. Kotkas, "From official supervision to self-monitoring: privatizing supervision of private social care services in Finland," Social Policy \& Administration, vol. 50, no. 5, pp. 599-613, 2016.

[23] L. Fabisiak, "Web service usability analysis based on user preferences," Journal of Organizational and End User Computing, vol. 30, no. 4, pp. 1-13, 2018.

[24] S. Wang, "Innovation of tourism public service mechanism of wisdom tourism based on neural network," Boletin Tecnico/ Technical Bulletin, vol. 55, no. 20, pp. 82-89, 2017.

[25] R. Engelbrecht-Wiggans and E. Katok, "A direct test of risk aversion and regret in first price sealed-bid auctions," Decision Analysis, vol. 6, no. 2, pp. 75-86, 2016.

[26] S. Opper, V. Nee, and H. J. Holm, "Risk aversion and guanxi activities: a behavioral analysis of CEOs in China," Academy of Management Journal, vol. 60, no. 4, pp. 1504-1530, 2017.

[27] M. Berardi, "Endogenous time-varying risk aversion and asset returns," Journal of Evolutionary Economics, vol. 26, no. 3, pp. 581-601, 2016.

[28] L. Eeckhoudt, L. Liu, and J. Meyer, "Restricted increases in risk aversion and their application," Economic Theory, vol. 64, no. 1, pp. 1-21, 2017.

[29] C.-L. Wei and C.-T. Ho, "Exploring signaling roles of service providers' reputation and competence in influencing perceptions of service quality and outsourcing intentions," Journal of Organizational and End User Computing, vol. 31, no. 1, pp. 86-109, 2019.

[30] M. Carey, “Journey's end? From residual service to newer forms of pathology, risk aversion and abandonment in social work with older people," Journal of Social Work, vol. 16, no. 3, pp. 344-361, 2016.

[31] K.-H. Lee and S. S. Hyun, "A model of value-creating practices, trusting beliefs, and online tourist community behaviors," International Journal of Contemporary Hospitality Management, vol. 28, no. 9, pp. 1868-1894, 2016.

[32] S. Oh, J. Rhodes, and R. Strong, "Impact of cost uncertainty on pricing decisions under risk aversion," European Journal of Operational Research, vol. 253, no. 1, pp. 144-153, 2016.

[33] T. O’Donoghue and J. Somerville, "Modeling risk aversion in economics," Journal of Economic Perspectives, vol. 32, no. 2, pp. 91-114, 2018.

[34] Z. Chang, S. Song, Y. Zhang, J.-Y. Ding, R. Zhang, and R. Chiong, "Distributionally robust single machine scheduling with risk aversion," European Journal of Operational Research, vol. 256, no. 1, pp. 261-274, 2017.

[35] S. Nicholson-Crotty, J. Nicholson-Crotty, and S. Fernandez, "Performance and management in the public sector: testing a model of relative risk aversion," Public Administration Review, vol. 77, no. 4, pp. 603-614, 2017.

[36] M. Yazdi, "Retracted article: an extension of the fuzzy improved risk graph and fuzzy analytical hierarchy process for determination of chemical complex safety integrity levels," International Journal of Occupational Safety and Ergonomics, vol. 25, no. 4, pp. 551-561, 2019.
[37] A. Liu, Y. Xiao, H. Lu, S. B. sai, and W. Song, "A fuzzy threestage integrated multi-criteria decision-making approach based on customer needs for sustainable supplier selection," Journal of Cleaner Production, vol. 239, no. 5, p. 118043, 2019.

[38] F. Salehian, J. Razmi, and F. Jolai, "A hybrid ranking approach based on fuzzy analytical hierarchy process and data envelopment analysis: road maintenance and transport organization of Iran," Journal of Intelligent \& Fuzzy Systems, vol. 34, no. 4, pp. 2373-2383, 2018.

[39] B. Cao, J. Zhao, P. Yang et al., "Multiobjective feature selection for microarray data via distributed parallel algorithms," Future Generation Computer Systems, vol. 100, pp. 952-981, 2019. 